\title{
Noninvasive Diagnosis of Pseudoaneurysm of the Left Ventricle
}

\author{
Irfan Sabah, * M.D., Junichi Yoshikawa, M.D., Hiroshi Kato, M.D., \\ Takane Owaki, M.D., Koji Yanagihara, M.D., Fukumaru \\ Okumachi, M.D., and Yoshihiro Takagi, M.D.
}

\begin{abstract}
Summary
The echocardiographic, scintigraphic, angiocardiographic and autopsy correlations in a patient with left ventricular pseudoaneurysm are presentcd. Interruption of the echo of the left ventricular wall and radioisotope image of pseudoaneurysm and its communication channel are demonstrated for the first time. The striking similarity of the radioisotope image to the angiographic image is noted.

This study suggests that echocardiography has capability to visualize left ventricular wall defects, such as the perforation seen in this case and radioisotope ventriculography is equivalent to the invasive contrast technique. Both of the methods seem to be safe and specific for the diagnosis of left ventricular pseudoaneurysm.
\end{abstract}

\section{Additional Indexing Words :}

Myocardial infarction Echocardiography Radioisotope scintigraphy Angiocardiograhy Cardiac rupture

DSEUDOANEURYSMS of the left ventricle are thought to be rare because 1 repture of the free cardiac wall is generally considered rapidly fatal. The literatures concerning myocardial infarction complicated by cardiac rupture show a progressive change in the perspective concerning this entity. ${ }^{1,3,(6)}$ However the incidence of cardiac free wall rupture is as high as 5 to $10 \%$ after myocardial infarction. ${ }^{11,4\}}$ Pseudoaneurysm is one possible consequence of free wall rupture and instead of being immediately fatal, some cases may be compatible with survivial and seem to be amenable to surgical care even in the acute phase of myocardial infarction.11.91,10) Therefore, a safe and accurate diagnostic method for early clinical detection is desirable.

On the other hand, angiography plays an essential role in the diagnosis of pseudoaneurysm, but lacks specificity and is less useful in the early diagnosis

From the Department of Cardiology, Kobe Municipal Cientral Hospital, Kano-cho 1-5, Ikuta-ku, Kobe, Japan.

* Present addres: Department of Cardiology, Gühane Medical Academy, Etlik, Ankara, Turkey.

Address for reprint: Dr. Irfan Sabah, Department of Cardiology, Güllane Medical Academy, Etlik, Ankara, Turkey.

Received for publication April 24, 1978. 
aneurysm..$^{2) 51,11)}$ Unfortunately, only a limited number of cases are reported in the literature where this diagnosis could be made with confidence. ${ }^{1), 4), 11}$ ) Echocardiography is a safe and more accurate diagnositc method to visualize pseudoaneurysm. ${ }^{4}$ In this paper we described the echocardiographic features and the radiosiotope angiographic study of a patient with left ventricular pseudoaneurysm.

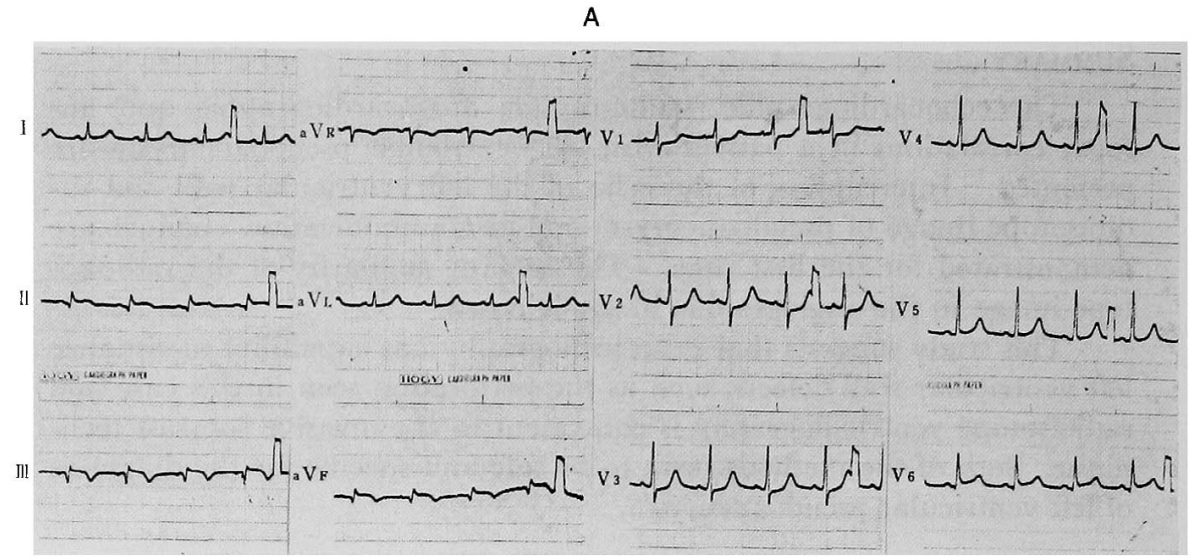

B

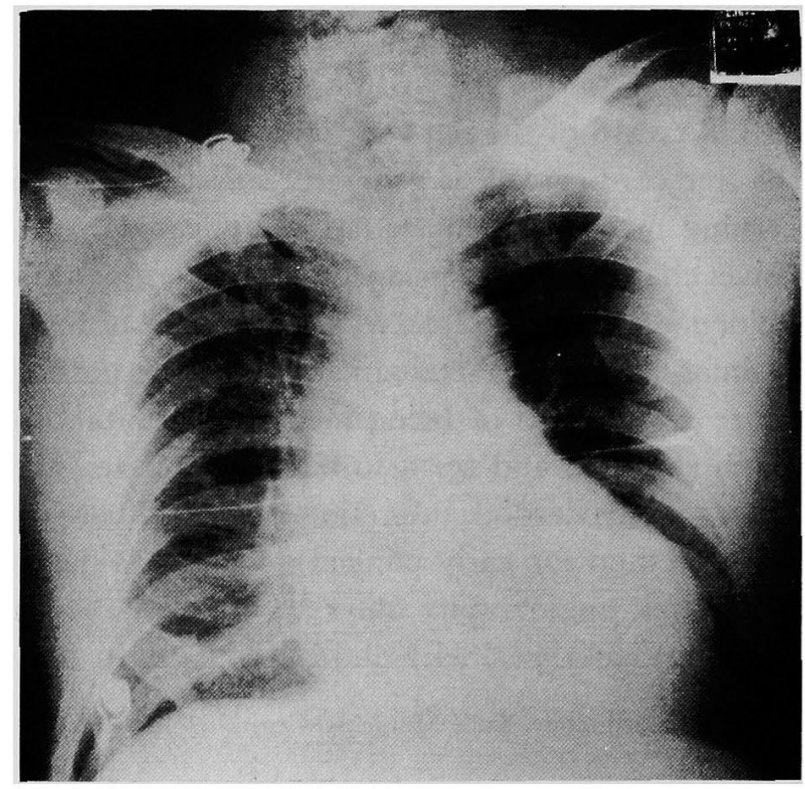

Fig. 1. Electrocardiogram and roentgenogram. Electrcardiogram shows inferior myocardial infarction with ST-T elevation in leads II, III, and aVF. Postero-anterior roentgenogram reveals pulmonary congestion and cardirmegaly with prominence of the left ventricle. 


\section{CASE Report}

A 68-year-old male was admitted to our department on July 21, 1977 with a chest pain, dizziness, and syncope. On examination, he was in sinus rhythm. The peripheral pulses were weak and fast with a rate of 116 beats/min, arterial blood pressure was $60 / 0 \mathrm{mmHg}$. Venous congestion and hepatomegaly were present, but
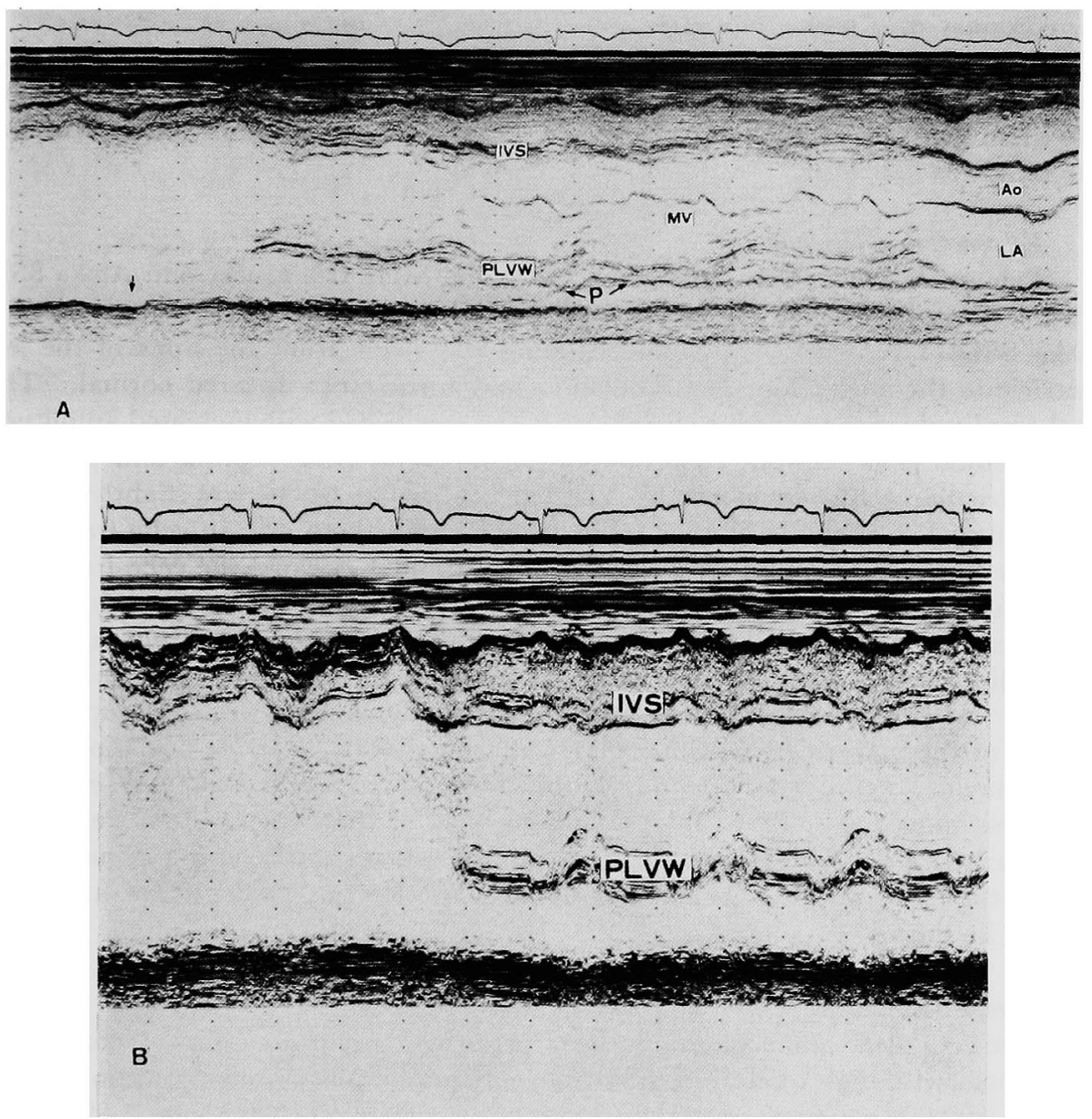

Fig. 2. M-mode scan from the apex to the base (A) and echocardiogram recorded with the ultrasound beam directed through the pseudoaneurysm (B). At the level of anterior mitral leaflet (MV), there is an echo-free space posterior to the left ventricular wall and pericardium (P). At the level of anterior and posterior mitral leaflets the pericardium angled posteriorly (arrows) and continued with outer contour of the echo-free space. When the ultrasound beam is moved further posteriorly and inferiorly, sudden interruption of left ventricular wall and anterior deviation of interventricular septum (IVS) are observed. At this level, the posterior wall of the echo-free space shows posterior motion in systole (arrow). These chocardiographic findings are typical for a pseudoaneurysm. 
no peripheral edema was noted. The heart sounds werc weak and no murmurs were heard. There was a slight rales on ausculatation of the right lung. The electrocardiogram (Fig. 1A) showed inferior myocardial infarction with ST elevation in leads II, III, and aVF. The chest X-ray showed pulmonary congestion and cardiomegaly with prominence of the left ventricule (Fig. 1B). Cardiac output determined by the thermodilution technique at bed side was $3.15 \mathrm{~L} / \mathrm{min}$. Despite the conservative treatment, the blood pressure remained about $60 \mathrm{mmHg}$. On the same day of hospitalization, the patient underwent intraaortic ballon pumping in our coronary care unit.

On July 25, 1978, physical examination revealed normal heart rate of 94 beats/ min and blood pressure was $110 / 70 \mathrm{mmHg}$. The lung was normal on auscultation and there was no pulmonary congestion on chest X-ray. The intraaortic balloon pumping was taken off.

\section{Echocardiographic study:}

Echocardiograms were obtained with a $2.25 \mathrm{MHz}$ transducer and Aloka SSD 110 instrument. Returning signals were recorded on photographic paper with a Aloka SSD-71 recorder. M-Mode scanning was made from the apex of the left ventricle to the aorta (Fig. 2). The aorta and aortic cusps apeared normal. The total amplitude of the anterior mitral leaflet was diminshed with increased amplitude of presystolic peak motion. The motion of interventricular septum and posterior left ventricular wall were normal. The left ventricular cavity was slightly dilated $(\mathrm{Dd}=5.8 \mathrm{~cm})$. At the level of anterior mitral leaflet there was an echo-free space posterior to the left ventricular wall and pericardium. Because the echo-free space was seen behind of the pericardium of left ventricular wall, it was thought not to be pericardial effusion. At the level of anterior and posterior mitral leaflet, the pericardium was angled posteriorly and the dimension of echo-free space was increased. Moving the transducer further posteriorly and inferiorly abrupt interruption of the posterior left ventricular wall and slightly anterior deviation of interventricular septum were shown. At this level, the posterior wall of the echo-free space was moved posteriorly in systole. In view of the clinical history and very characteristic echocardiographic findings, we thought that this was a pseudoaneurysm of the left ventricle. This diagnosis was confirmed by angiographic and postmortem findings.

\section{Isotope ventricuiography:}

$99 \mathrm{mTcO}_{4}$ left ventriculography was performed using an Ohio nuclear series 410 camera with high resolution collimeter. Left anterior oblique projections, each taken to 300,000 counts were obtained on polroid prints after single pass $99 \mathrm{mTcO}$, administration. Fig. 3 shows left ventricular scintigram obtained from the patient in our hospital. There was a cavity at the posterior-inferior aspect of the left ventricle (LV) which was diagnosed a pseudoaneurysm (A) by echocardiography. There was a communication between the left ventricle and aneurysm which was smaller than the largest diameter of pseudoaneurysm. The striking similarity of this frame to the angiographic study of Fig. 4 was noted.

Catheterization and angiography:

On September 7, 1977, cardiac catheterization and angiography was perform- 


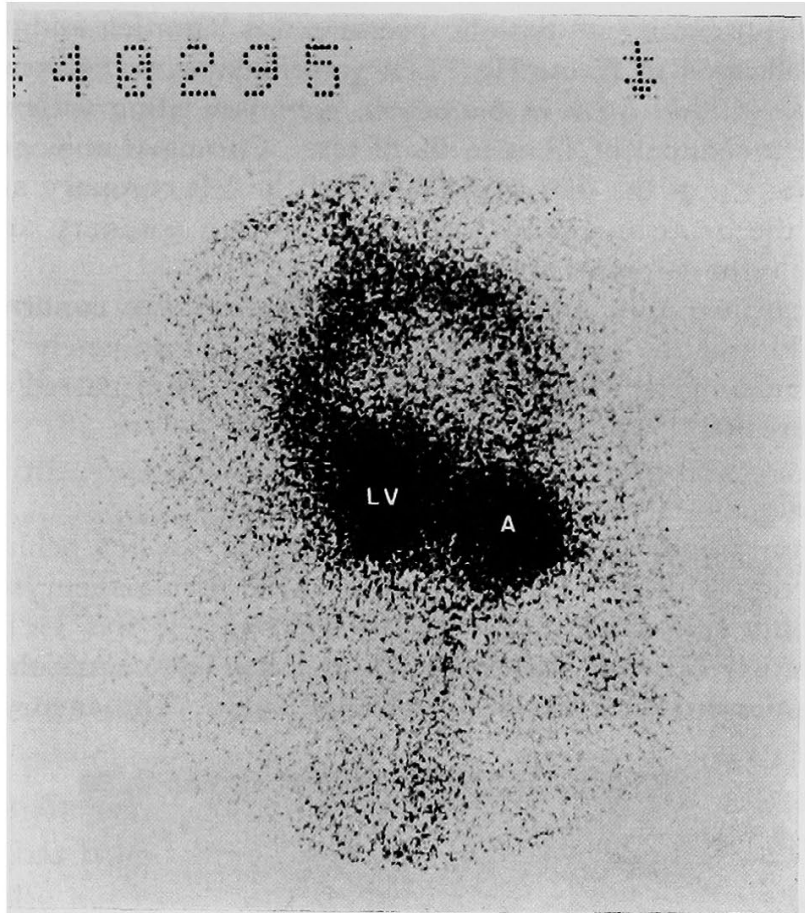

Fig. 3. Radioisotope ventriculogram in left anterior oblique position obtained at end-diastole. A cavity lies along the postero-inferior aspect of the left ventricle (LV) is pseudoaneurysm (A). There is communication between the left ventricle and pseudoaneurysm. Note the striking similarity of this frame to angiographic image (Fig. 4).

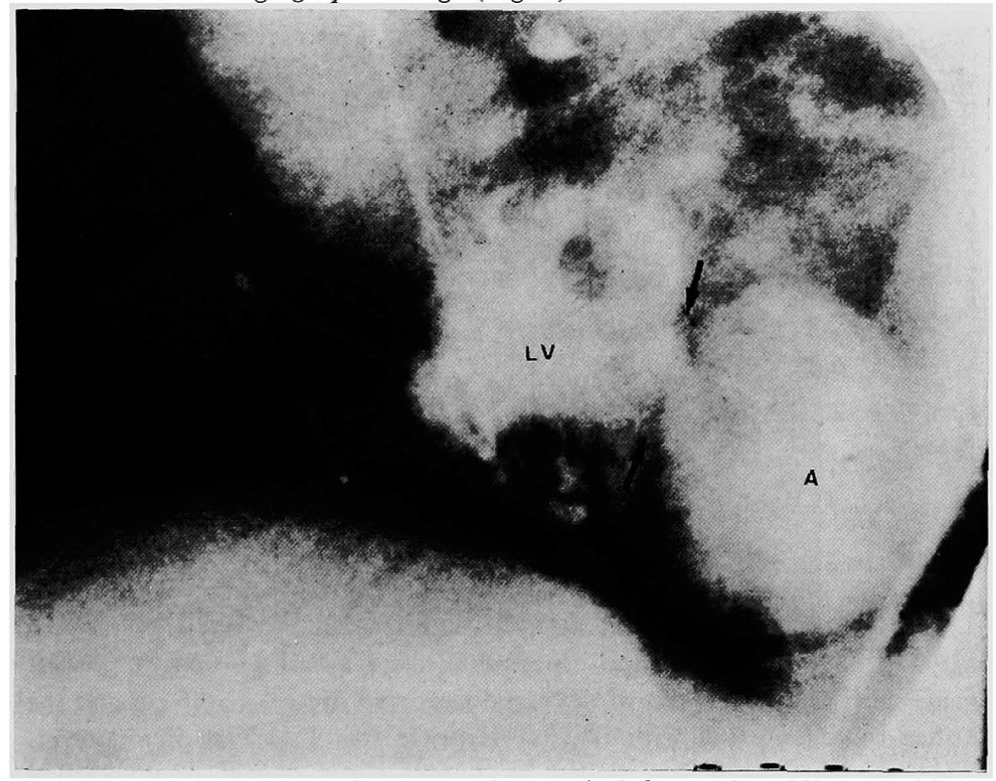

Fig. 4. Left ventricular cineangiogram in left anterior oblique position. The pseudoaneurysm lies along the postero-inferior aspect of the left ventricle. Black arrows point out communicating channel. 
ed. The left ventricular end-diastolic pressure was $9 \mathrm{mmHg}$ and after cineangiography it was elevated to $25 \mathrm{mmHg}$. Left ventricular cineangiogram (Fig. 4) revealed an aneurysm $3.5 \times 5 \mathrm{~cm}$ in diameters, communicating with the left ventricular lumen via a channel of $1 \mathrm{~cm}$ in diameter. Coronary angiography revealed complete obstruction of the diagonal branch of the left coronary artery, complete obstruction of the acute marginal branch of the righ coronary artery and $50 \%$ occlusion of the right coronary artery.

The echocardiographic and scintigraphic diagnosis was confirmed by the angiographic study and the operation was decided. Unfortunetely 5 days prior to the operation, suddenly atrio-ventricular block and shock occurred and the patient died shortly thereafter.

\section{Autopsy finding :}

Postmortem examination revealed a pseudoaneurysm lied behind the left ventricle in conjuction with it. The dimensions of the pseudoaneurysm were $4 \times 5 \times$ $5 \mathrm{~cm}$. The orifice communicating with the left ventricle was $1 \times 1.5 \mathrm{~cm}$ in diameter. The junction between the aneurysm and the left ventricular wall showed sudden interruption in continuity of myocardial tissue. The aneurysm was walled

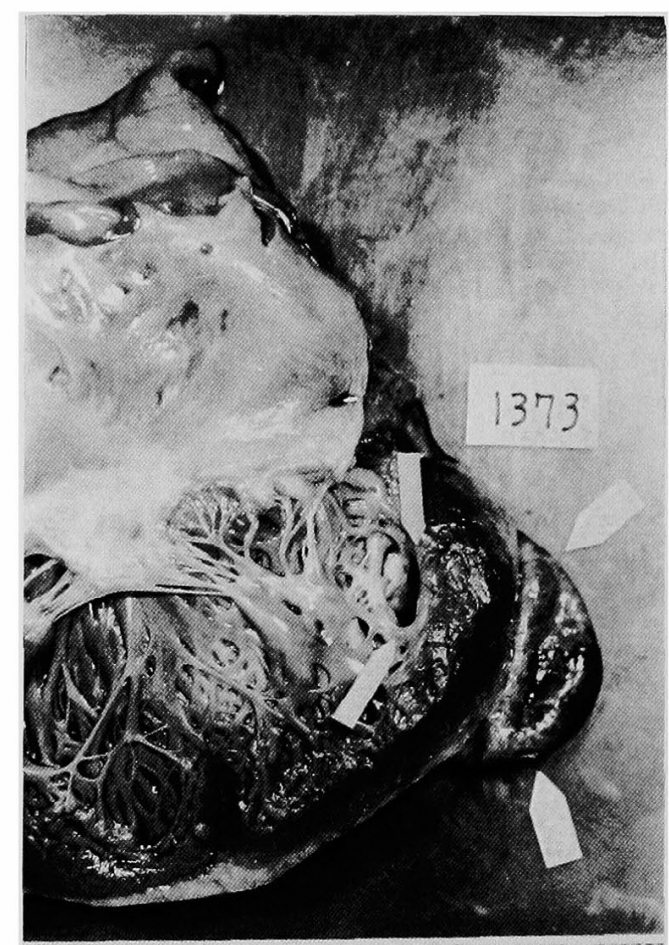

Fig. 5. Autopsy findings. Section through apical portion of the left ventricle. The dimensions of the pseudoaneurysm were $4 \times 5 \times 5 \mathrm{~cm}$ and the orifice communicating with the left ventricle was $1 \times 1.5 \mathrm{~cm}$ in diameter. The pseudoaneurysm was walled by fibrous tissue devoid of myocardial elements. There was a perforation in the fundus of aneurysm with a diameter of $0.5 \mathrm{~cm}$. 
by hyaline fibrous tissue without any muscle bundles. An adherent blood clot was present with some degree of organization. The parietal pericardium was adherent to the other surface of the aneurysm. There was a perforation in the fundus of aneurysm with a diameter of $0.5 \mathrm{~cm}$. Death was the result of the rupture of pseudoaneurysm.

\section{Discussion}

Rupture of the ventricle usually results in fatal hemopericardium, but confinement by the pericardium may limit hemorhage and result in formation of a fibrotic pseudoanuerysm. True aneurysms are more commonly formed, but they rupture only rarely. ${ }^{21,11}$

Van Tassel and Edwards ${ }^{11}$ found 9 cases of pseudoaneurysm in their autopsy series of 40 cardiac ruptures. The anatomic locations were equally distributed over the left ventricle. Because true aneurysms seldom rupture, it is important to differentiate the 2 types when an aneurysm is suspected and to treat pseudoaneurysm in a more aggressive surgical manner. ${ }^{7,10}$ Since a pseudoaneurysm closely mimics a true aneurysm in all aspects, ventriculography has been employed to provide a diagnosis. ${ }^{6,7)}$ True aneurysm characteristically have wide openings into the left ventricle whereas pseudoaneurysm most often have a narrow neck leading into the fundus. ${ }^{41,11)}$ The adequate visualization of the pseudoaneurysm, particularly of the communication with the left ventricular cavity, is largely dependent upon the careful examination and proper projections during filming. ") However, only a few cases are reported in the literatures, where the diagnosis of pseudoaneurysm was made with confidence. ${ }^{1,4,111 \text { ? }}$

Echocardiography and radioisotope ventriculography are more accurate and safer techniques for detection of cardiac structures and evaluation of left ventricular function ${ }^{8), 15)}$ The echocardiographic experience with left ventricular aneurysm is extremely limited and was described only by Roelandt et $\mathrm{al}^{4)}$. They reported echo-free space behind the left ventricular wall in a patient with left ventricular pseudoaneurysm. In addition to this finding, we described interruption of the echo of the left ventricular wall for the first time. This echocardiographic findings were well correlated with the angiographic and postmortem findings, where the interruption of the echo was due to the ruptured left ventricular wall and mouth of aneurysm and the echo-free space was the lumen of pscudoaneurysm. The study suggests that echocardiography has capability to visualize ventricular wall defects, such as the perforation in this case.

The value of the radioisotope ventriculography in the diagnosis of left ventricular aneurysm has been demonstrated, ${ }^{12)-15}$ but there has been no 
previous report on the diagnosis of left ventricular pseudoaneurysm by radioisotope ventriculography. In this study we demonstrated the left ventricular pseudoaneurysm and its communication channel using single pass isotope ventriculography. Scintigraphic findings were correlated with echocardiographic and angiocardiographic findings. The present study suggests that single pass ventriculography is sensitive and specific indicator of left ventricular pseudoaneurysm. Single pass isotope ventriculography is easily performed, dose not alter left ventricular function and can be performed in any projections. If a radioisoptoe with short biological half life is used, studies can be repeated after 2 to 3 hours. ${ }^{15}$

The fatal rupture is a common complication of pseudoaneurysm. Our patient was awaiting operation when the fatal rupture of the aneurysm occurred. The frequency of rupture and subsequent death stimulates early diagnosis and surgical resection of pseudoaneurysm.

On the basis of our experience in the present study, we recommend the routine use of echocardiography and isotope ventriculography in patients with clinical signs and symptoms suggestive of left ventricular aneurysm.

\section{ReFERENCE}

1. Van Tassel A, Edwards JE: Rupture of the heart complicating myocardial infarction. Analysis 40 cases including nine examples of left ventricular false aneurysm. Chest 61: 104, 1972

2. Chesler E, Korns ME, Semba T, Edward JE: False aneurysm of the left ventricle following myocardial infarction. Am J Cardiol 23: 76, 1969.

3. Fallah-Nejad M, Abelson DM, Blakemore WS: Left ventricular pseudoaneurysm. Chest 61: 90,1972

4. Roelandt J, Van Den Brand M, Vletter WB, Nauta J, Hugenholtz WB: Echocardiographic diagnosis of pseudoaneurysm of the left ventricle. Circulation 52: 466, 1975

5. Nacim F, De la Maza LM, Robbins S: Cardiac rupture during myocardial infarction. A review of 44 cases. Circulation 45: 1231, 1972

6. Killen D, Gobbel WC: Post-traumatic aneurysm of left ventricle. Circulation 39: 101, 1969

7. Smith RC, Goldberg H, Bailey CP: Pseudoaneurysm of the left ventricle: diagnosis by direct cardioangiography. Surgery 42: 936, 1957

8. Jacobs JJ, Feigenbaum H, Corya BC, Phillips JF: Detection of left ventricular asynergy by echocardiography. Circulation 48: 263, 1973

9. O'rourke MF: Subacute heart rupture following myocardial infarction. Clinical features of a correctable condition. Lancet 2: 124, 1974

10. Fitzgibbon GM, Hooper GD, Heggveit HA: Successful surgical treatment of post infarction external cardiac rupture. J Thorac Cardiovasc Surg 63:622, 1972

11. Bates JR, Leon Resnekov BS, Anagnostopoulos CF: Cardiac rupture-challenge in diagnosis and management. Am J Cardiol 40: 429, 1977

12. Rigo P, Murray M, Strauss HW, Pitt B: Scintiophographic evaluation of patients with suspected left ventricular aneurysm. Circulation 50: 985, 1974.

13. Drew D, Botvinick E, Schames D, Klausner S, Greenberg B, Shiller N, Carisson E, Parmley 
W: Radioisotope ventriculography is equalivalent to the invasive contrast technique. Circulation 53-54 (suppl II): II-109, 1976

14. Sharpe DN, Botvinick E, Shames D, Norman A, Chatterjec K, Parmley W: The clinical estimation of acute myocardial infarct size with $99^{\mathrm{m}}$ technetium pyrophosphate scintigraphy. Circulation 57: 307, 1978

15. Jengo AJ, Menda I, Blauffus A, Criley JM: Evaluation of left ventricular function (ejection fraction and segmental wall motion) by single pass radioisotopc angiography. Circulation 57: 326,1978 